( Е.Н. Дудинская ${ }^{1 *}$, О.Н. Ткачева', Н.В. Браилова' ${ }^{1}$ И.Д. Стражеско ${ }^{1}$, М.В. Шестакова²

'Российский национальный исследовательский медицинский университет им. Н.И. Пирогова, Российский геронтологический научно-клинический центр, Москва, Россия

${ }^{2}$ Национальный медицинский исследовательский центр эндокринологии, Москва, Россия

ОБОСНОВАНИЕ. Инсулинорезистентность способствует ускорению процессов старения, но ее скорость зависит от индивидуальных особенностей метаболизма. Одной из причин разной скорости старения у лиц с инсулинорезистентностью является изначально различная «генетическая защищенность» клеток, которую многие ученые связывают с репликативным клеточным старением.

ЦЕЛЬ. Изучение взаимосвязи состояния углеводного обмена и маркеров репликативного клеточного старения у лиц с различной чувствительностью к инсулину.

МЕтодЫ. В одномоментное исследование были включены 305 пациентов. Проведено изучение параметров углеводного обмена и биологии теломер (длина теломер лейкоцитов и активность теломеразы).

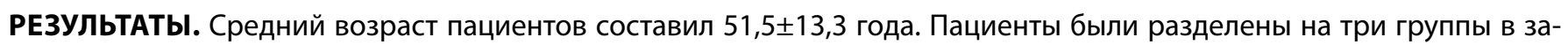
висимости от степени инсулинорезистентности: здоровые, с инсулинорезистентностью и с сахарным диабетом

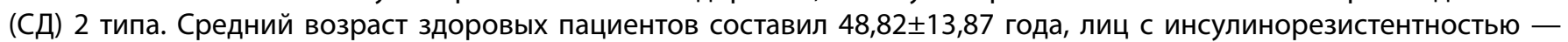

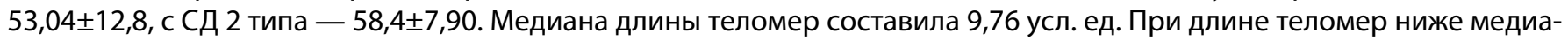
ны говорили о коротких теломерах $(n=153)$, при значении выше медианы - о длинных теломерах $(n=145)$. Медиана активности теломеразы составила 0,48 усл. ед. При активности теломеразы ниже медианы говорили о низкой активности теломеразы (n=92), при значении выше медианы — о высокой активности теломеразы (n=96). И длина теломер, и активность теломеразы прогрессивно снижаются по мере усиления инсулинорезистентности. У пациентов с диабетом преобладали короткая длина теломер и низкая активность теломеразы. Наибольшее влияние на риск выявления «коротких» теломер оказывает индекс инсулинорезистентности. У пациентов с инсулинорезистентностью повышение уровня гликированного гемоглобина увеличивает вероятность выявления «коротких» теломер в 2,4 раза, а при СД - в 4,26 раза, повышение глюкозы плазмы натощак - на 90\%, увеличение HOMA-IR - на 35\%. Нарастание инсулинорезистентности повышает риск выявления «низкой» активности теломеразы на 53\% и риск выявления «очень низкой» активности теломеразы на 92\%. Снижение инсулинорезистентности повышает шанс повышения активности теломеразы до «очень высокой» на $51 \%$.

ЗАКЛюЧЕНИЕ. Более короткие теломеры ассоциированы с более выраженными нарушениями углеводного обмена и более высокой степенью инсулинорезистентности. Дальнейшие исследования метаболического статуса необходимы для персонализации их образа жизни и целей лечения.

КЛЮЧЕВЫЕ СЛОВА: инсулинорезистентность; теломеры; теломераза; старение, диабет.

\title{
TELOMERE BIOLOGY AND METABOLIC DISORDERS: THE ROLE OF INSULIN RESISTANCE AND TYPE 2 DIABETES
}

(c) Ekaterina N. Dudinskaya1*, Olga N. Tkacheva1', Nataliya V. Brailova1', Irina D. Strazhesko², Marina V. Shestakova²

'Pirogov Russian National Research Medical University of Ministry of Health of Russian Federation "Russian Gerontology Research and Clinical Centre", Moscow, Russia

${ }^{2}$ The National Medical Research Center for Endocrinology of Ministry of Health of Russian Federation, Moscow, Russia

BACKGROUND: Insulin resistance accelerates the aging process, but its speed depends on the individual characteristics of the metabolism. One of the reasons for the different aging rates in individuals with insulin resistance is the initially different "genetic protection" of cells, which many scientists associate with replicative cellular aging.

AIMS: to study the relationship between the state of carbohydrate metabolism and markers of replicative cell aging in individuals with different sensitivity to insulin.

MATERIALS AND METHODS: The observation study included 305 patients. The parameters of glucose metabolism and telomere biology were studied. 
RESULTS: The mean age of the patients was $51.5 \pm 13.3$ years. Patients were divided into three groups depending on presence of insulin resistance: healthy, with insulin resistance and with type 2 diabetes. The mean age of healthy patients was $48.82 \pm 13.87$ years, in insulin resistance group $-53.04 \pm 12.8$, in 2 diabetes mellitus $-58.4 \pm 7.90$. The median telomere length was 9.76 . The median telomerase activity was 0.48 . Both telomere length and telomerase activity progressively decrease as insulin resistance increases. In patients with diabetes, short telomere lengths and low telomerase activity predominated. The insulin resistance index has the greatest impact on the risk of detecting "short" telomeres. In patients with insulin resistance, an increase in glycated hemoglobin increases the likelihood of detecting short telomeres by 2.4 times, and in diabetes mellitus by 4.26 times, an increase in fasting plasma glucose by $90 \%$, and an increase in HOMA-IR by $35 \%$. An increase in insulin resistance increases the risk of detecting «low» telomerase activity by $53 \%$ and the risk of detecting «very low» telomerase activity by $92 \%$. A decrease in synsulin resistance increases the chance of increasing telomerase activity to «very high» by $51 \%$.

CONCLUSION: Shorter telomeres are associated with more pronounced disorders of carbohydrate metabolism and a higher degree of insulin resistance. Further studies of metabolic status are necessary to personalize their lifestyle and treatment goals.

KEYWORDS: Insulin resistance; telomere, telomerase; aging, diabetes.

\section{ВВЕДЕНИЕ}

Одной из бурно обсуждаемых причин различной скорости процессов старения у лиц с инсулинорезистентностью (ИР) является изначально разная «генетическая защищенность» клеток и тканей от воздействия внешних повреждающих факторов [1]. Важнейшую роль в этом вопросе играют процессы репликативного клеточного старения. В качестве его биомаркеров изучаются такие параметры, как длина теломер (ДТ) и активность теломеразы (АТ), которые вместе составляют понятие «биология теломер». Теломеры являются концевыми участками ДНК, состоящими из повторяющейся последовательности нуклеотидов TTAGGG. Основная задача теломер состоит в поддержании стабильности генома, защищая ДНК от повреждений и линейные концы хромосом от слияния между собой. ДНК теломер соматических клеток при каждом делении клеток постепенно укорачивается из-за неполной репликации концевых участков. При достижении критически короткой длины теломерной ДНК наступает старение клетки, а именно неспособность ее к дальнейшему делению и восстановлению повреждений [2].

Поддерживает ДТ на необходимом для деления уровне фермент теломераза, достраивающая теломерные повторы ДНК, которая относится к классу РНК-зависимых ДНК-полимераз и включает в себя теломеразную обратную транскриптазу (TERT) и теломеразную PHK (TERC), используемую для синтеза теломерной ДНК в качестве матрицы [3].

Что в большей степени связано с ускоренным старением - репликативное клеточное старение или воздействие гиперинсулинемии при ИР? С одной стороны, ИР, будучи связана с процессами хронического воспаления, может способствовать укорочению теломер в стволовых клетках и последующему снижению их функциональной активности. Об этом свидетельствуют немногочисленные исследования, демонстрирующие высокую взаимосвязь скорости укорочения теломер и степени ИР [2, 4]. С другой стороны, сама по себе ИР может быть результатом нарушения процессов дифференциации мезенхимальных прогениторных клеток в зрелые адипоциты при изначально короткой ДТ [5].

Следует отметить, что количество исследований, посвященных взаимосвязи ИР и биологии теломер, доволь- но немногочисленно. Эти вопросы крайне мало изучены в российской популяции, тогда как предупреждение патологических изменений на раннем этапе ИР представляется наиболее важным в проведении ранней и персонализированной профилактики сердечно-сосудистых заболеваний (СС3).

\section{ЦЕЛЬ}

Целью исследования явилось изучение взаимосвязи состояния углеводного обмена и маркеров репликативного клеточного старения у лиц с различной чувствительностью к инсулину.

\section{МЕТОДЫ}

Дизайн исследования: обсервационное одноцентровое одномоментное неконтролируемое исследование.

\section{Критерии включения:}

- мужчины и женщины в возрасте от 25 лет и старше;

- подписанное информированное согласие на участие в исследовании.

Критерии невключения: сахарный диабет (СД) 1 типа и другие специфические типы СД, кетоацидотические, гипогликемические, лактат-ацидозные события в анамнезе, морбидное ожирение (индекс массы тела (ИМТ) $>40$ кг/м²), семейная гиперхолестеринемия, клинические проявления атеросклероза (ишемическая болезнь сердца, цереброваскулярная болезнь, хронические облитерирующие заболевания периферических артерий), артериальная гипертония (АГ) 2 и 3 степени, вторичные формы АГ, регулярный прием гипотензивных и сахароснижающих препаратов, операции реваскуляризации сосудов сердца и периферических артерий, диабетические микроангиопатии (препролиферативная, пролиферативная и терминальная стадии диабетической ретинопатии, хроническая болезнь почек 3, 4 и 5 стадии), клинически значимые нарушения ритма сердца и проводимости; кардиомиопатии, хроническая сердечная недостаточность II-IV классов (NYHA), наличие клапанных пороков сердца; хронической печеночной и почечной недостаточности, онкологических заболеваний, беременности, период лактации, отказ от участия в исследовании. 
Условия проведения

В исследование были включены 305 пациентов (106 мужчин и 199 женщин) из числа обратившихся в ФГБУ «Государственный научно-исследовательский центр профилактической медицины» Минздрава России (ФГБУ «ГНИЦПМ» Минздрава России) с июня 2012 г. по октябрь 2013 г. с целью профилактического консультирования, не имевшие клинических проявлений сердечно-сосудистых заболеваний (ССЗ), связанных с атеросклерозом, и других хронических неинфекционных заболеваний.

\section{Продолжительность исследования}

Продолжительность исследования составила 1 год. В 2014 г. было выполнено одномоментное поперечное исследование.

Описание медицинского вмешательства

Исследование проводилось в два этапа.

\section{На этапе скрининга проводились:}

- сбор жалоб и анамнеза;

- изучение медицинской документации;

- антропометрические измерения.

После установления соответствия критериям включения, критериям исключения, подписания информированного согласия пациент включался в исследование. При выявлении критериев исключения обследуемый исключался из исследования на любом этапе.

Основной исход исследования: оценка биохимических параметров углеводного обмена, а также их взаимовлияние с ДТ и АТ.

\section{Анализ в подгруппах}

Пациенты были разделены на три группы в зависимости от степени нарушения углеводного обмена: здоровые (без нарушений углеводного обмена, $n=175$ ), лица с ИР (индекс HOMA-IR $\geq 2,5 ; n=80$ ) и пациенты с СД 2 типа (СД2, n=50).

\section{Методы регистрации исходов}

\section{Этап скрининга (1-й этап).}

- Массу тела измеряли на напольных весах с точностью до 1 кг. Рост измеряли на ростомере с точностью до 1 см. ИМТ вычисляли по формуле: масса тела (кг)/[рост (м) $]^{2}$. Массу тела считали нормальной

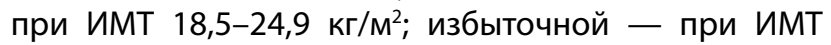

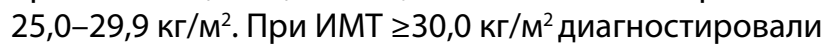
ожирение; при соотношении объема талии к объему бедер (ОТ/ОБ) >0,9 диагностировали абдоминальное ожирение.

- Объективный осмотр, включающий оценку уровня артериального давления (АД) (мм рт. ст.) и частоты сердечных сокращений (ЧСС) (уд/мин). Уровень АД измерялся на обеих руках после 10-минутного отдыха в положении сидя 3 раза с интервалом 3 минуты на калиброванном приборе с использованием плечевой манжеты (HEM-7200 M3, Omron Healthcare, Kyoto, Japan). В базу данных включали среднее из 3 измерений. Повышенным считалось АД $\geq 140 / 90$ мм рт.ст.;

- регистрация электрокардиограммы в 12 отведениях проводилась с помощью электрокардиографа Cardiovit at-10 plus, Schiller (Швейцария);
- проба с физической нагрузкой (тредмил-тест по протоколу Bruce) проводилась для исключения преходящей ишемии миокарда (Intertrack, Schiller (Швейцария));

- трансторакальная эхокардиография проводилась для исключения ишемической болезни сердца (ИБС), кардиомиопатий, пороков сердца по стандартной методике (Philips iu22, Нидерланды).

Включенным в исследование пациентам проводились основные методы исследования (2-й этап).

Лабораторные исследования выполнялись на базе лаборатории ФГБУ ГНИЦПМ Минздрава России. В утренние часы с 9:00 до 10:00 в процедурном кабинете всем пациентам из кубитальной вены системой BD Vacutainer ${ }^{\circledR}$ медсестрой проводился забор венозной крови. Процедура проводилась в состоянии покоя, после 30-минутного отдыха, в положении сидя. Перед процедурой пациентам запрещалось курить и принимать пищу в течение 12 ч.

\section{Перечень исследований включал:}

- общеклинический анализ крови по стандартной методике;

- определение уровня глюкозы плазмы натощак (ГПН) глюкозооксидазным методом. Референсные значения 3,9-6,4 ммоль/л. Гипергликемия натощак диагностировалась при ГПН 26,1 ммоль/л. Повышенным уровнем ГПН при анализе считалось содержание глюкозы $\geq 6,1$ и <7,0 ммоль/л;

- определение иммунореактивного инсулина (ИРИ) методом хемилюминесценции. Референсные значения ИРИ 2-25 мкЕд/мл. Расчет индекса инсулинорезистентности (ИР) HOMA-IR (Homeostasis Model Assessment of Insulin Resistance) проводился по формуле:

Концентрация ГПН (ммоль/л) × Концентрация инсулина в крови натощак (мкЕД/л) / 22,5.

При индексе HOMA-IR >2,5 диагностировалась ИP [6];

- лицам с риском развития СД2 (возраст >45 лет, наличие АГ, семейный анамнез СД, гестационный СД в анамнезе), при уровне ГПН 6,1-6,9 ммоль/л и при уровне гликированного гемоглобина $\left(\mathrm{HbA}_{1 c}\right)$ 6,0-6,5\% проводился пероральный глюкозотолерантный тест (ПГТТ). После забора крови натощак больные принимали внутрь 75 г безводной глюкозы, растворенной в 300 мл воды. Через 2 ч производился повторный забор крови. В период проведения теста исключались курение, прием пищи и физические нагрузки. Нарушенной толерантностью к глюкозе (НТГ) считалось состояние, при котором уровень постпрандиальной глюкозы (ППГ) через 2 ч после ПГТТ был $\geq 7,8$ ммоль/л и $\leq 11,1$ ммоль/л [7];

- определение уровня $\mathrm{HbA}_{1 с}$ методом жидкостной хроматографии. Референсные значения - менее $6,5 \%$.

Диагноз СД 2 типа устанавливался: 1) при уровне ГПН $\geq 7$ ммоль/л или уровне ППГ $\geq 11,1$ ммоль/л; 2) при уровне $\mathrm{HbA}_{1 \mathrm{c}} \geq 6,5 \%$ [7].

Определение ДТ проводилось на базе лаборатории ФГБОУ ВО «Московский государственный университет имени М.В. Ломоносова». ДТ определялась в лейкоцитах 
крови на геномной ДНК. В ходе анализа методом полимеразной цепной реакции (ПЦР) в реальном времени определялось количество ДНК с теломерной последовательностью в геноме. Одновременно проводилась ПцР в реальном времени к однокопийному участку геномной ДНК. Отношение количеств теломерной и однокопийной матриц было пропорционально ДТ. Одновременно с одними реактивами (за исключением праймеров) подготавливались стоковые смеси 1,25x (1х смесь: буфер для ПЦР 1x (Fermentas 10x PCR Hotstart buf $+\mathrm{KCl}), \mathrm{MgCl}_{2} 2 \mathrm{MM}$, dNTP 0,2 мM, 0,25 пмоль/мкл каждого праймера, 0,05 ед/мкл полимеразы Maxima (Fermentas), Sybr Green I 0,2x). Для теломерной ПЦР использовалась пара праймеров Tel1 ggttttgagggtgagggtgagggtgagggtgagggt и Tel2 tcccgactatccctatccctatccctatccctatcccta. Для контрольной ПЦР использовалась пара праймеров 36В4u cagcaagtgggaaggtgtaatcс и 36В4d cccattctatcatcaacgggtacaa. Рассчитывали разницу циклов порогов амплификации теломер и однокопийного гена и на их основе - относительное значение ДТ. В качестве реперной точки использовалась геномная ДНК из клеточной линии НЕК. Единица измерения - условные единицы [8].

Анализ АТ проводился на чисто выделенной моноцитарной фракции клеток крови (примесь эритроцитов затрудняет анализ), 10000 клеток на 1 анализ. Клетки моноцитов лизировали буфером с мягким детергентом, отделяли экстракт. Для этого клетки, полученные из моноцитарного кольца на градиенте плотности Ficoll и после промывания буфером PBS, ресуспендировали в лизирующем буфере (10 мM Tris-HCI или 10 мM HEPES-KOH, $\mathrm{pH}$ 7,5, 1,0 мM MgCl, 1 мM EGTA, 5 мМ-меркаптоэтанол, 5\% глицерин, 0,5\% CHAPS, 0,1 мM PMSF), 1 мл на 0,1-10 млн клеток. Инкубировали 30 минут во льду. Центрифугировали 10 минут при $4^{\circ} \mathrm{C}$ на 15000 об/мин и отбирали надосадочный раствор. Экстракт делили на аликвоты и замораживали в жидком азоте. С полученным экстрактом проводилась теломеразная полимеразная реакция. Готовили 28 мкл смеси 1: 1x TRAPбуфер (1x TRAР-буфер: 20 мМ HEPES-KOH pH 8,3, 1,5 мМ $\mathrm{MgCl}_{2}, 63 \mathrm{MM} \mathrm{KCl}, 1 \mathrm{MM} \mathrm{EGTA,} \mathrm{0,1} \mathrm{мг/мл} \mathrm{BSA,} \mathrm{0,005 \%} \mathrm{v/v}$ Tween-20), по 20 мкM dNTP, 10 пмоль олигонуклеотида TS (aatccgtcgagcagagtt) и экстракт моноцитов или клеток контрольных клеточных линий. Реакционную смесь инкубировали 30 минут при $25^{\circ} \mathrm{C}$. Полученные продукты амплифицировали с помощью ПЦР в реальном времени. К смеси добавляли 1,5 ед. Таq-ДНК-полимеразы («Хеликон»), 10 пмоль олигонуклеотида ACX (gcgcggcttacccttacccttaccctaacc) и Sybr Green I до 0,2x концентрации в финальной смеси и проводили ПЦР-рв на приборе CFX-96: 35 с $94^{\circ} \mathrm{C}, 35$ с $50^{\circ} \mathrm{C}, 90$ с $72^{\circ} \mathrm{C}$ (30 циклов, амплификатор Mastercycler (Eppendorf, Германия)). Единица измерения - условные единицы.

\section{Этическая экспертиза}

Исследование выполнено в соответствии со стандартами надлежащей клинической практики (GoodClinicalPractice) и принципами Хельсинкской декларации. Протокол исследования одобрен независимым этическим комитетом ФГБУ «ГНИЦПМ» Минздрава России (Протокол заседания ЛЭК №09-01/14 от 7 октября 2014 г.). Все участники подписали информированное согласие на участие в исследовании.

\section{Статистический анализ}

Статистическая обработка данных выполнена при помощи статистической программы SPSS 23.0 (SPSS Inc., США). Вид распределения количественных переменных анализировали при помощи одновыборочного критерия Колмогорова-Смирнова. При параметрическом распределении данных результаты представляли как $\mathrm{M} \pm \mathrm{SD}$, где M - среднее, SD - стандартное отклонение; при непараметрическом - как Ме (25\%; 75\%), где Ме медиана, 25\% и 75\% - 25-й и 75-й процентили. Для корреляционного анализа использовали тест для непараметрических данных (Spearman). Для межгрупповых сравнений использовали критерий Краскела-Уоллиса (для количественных переменных) и $x^{2}$ Пирсона (для качественных переменных). Для выявления взаимосвязей между переменными использовали бинарную логистическую регрессию с вычислением отношения шансов (ОШ) и 95\% доверительного интервала (ДИ). Статистически значимыми считались различия при $\mathrm{p}<0,05$.

Промежуточные результаты

Промежуточные результаты исследования частично были ранее опубликованы в диссертациях И.Д. Стражеско (2019 г.) [1], Н.В. Браиловой (2017 г.) [9] и в работе Е.Н. Дудинской (2014 г.) [10].

\section{РЕЗУЛЬТАТЫ}

\section{Участники исследования}

После проведенного скрининга в исследование были включены 305 пациентов (106 мужчин и 199 женщин). Средний возраст всех обследуемых составил

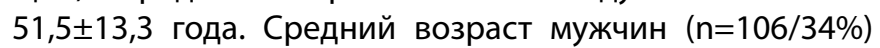
составил 55,73 $\pm 7,47$ года, средний возраст женщин (n=199/66\%) - 59,25 $\pm 8,05$ года.

Пациенты были разделены на три группы в зависимости от степени нарушения углеводного обмена:

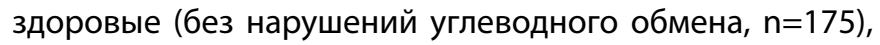
лица с ИР (индекс HOMA-IR $\geq 2,5, n=80$ ) и пациенты с СД2 $(\mathrm{n}=50)$. Средний возраст пациентов без нарушений углеводного обмена составил 48,82+13,87 года, лиц

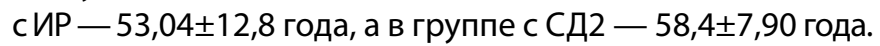
Длительность СД2 у пациентов с диабетом составила $0,9 \pm 0,09$ года.

\section{Основные результаты исследования}

Основные характеристики пациентов трех групп представлены в таблице 1. Жирным шрифтом выделены показатели, значения которых достоверно различались между группами.

При проведении сравнительного анализа выявлено, что пациенты трех групп достоверно различались по возрасту, параметрам углеводного обмена, уровням АД и антропометрическим данным. С увеличением степени нарушений углеводного обмена имелись тенденции к увеличению массы тела, ИМТ, ОТ, ОБ, уровней систолического и диастолического АД (САД и ДАД). В группе здоровых людей средний возраст был значимо меньше, чем в группах с углеводными нарушениями; распространенность АГ (АД $\geq 140 / 90$ мм рт. ст.) была минимальной (12,1 и 13,2\% соответственно). В группе больных СД2 средний возраст был самым большим 
Таблица 1. Клиническая характеристика участников исследования (n=305).

\begin{tabular}{|c|c|c|c|c|}
\hline Показатель & Здоровые (n=175) & ИP $(n=80)$ & СД2 (n=50) & $\mathbf{p}^{*}$ \\
\hline Возраст, годы & $48,8 \pm 13,8$ & $53,04 \pm 12,8$ & $58,4 \pm 7,90$ & $<0,001$ \\
\hline Мужской пол, n (\%) & $48(27,6)$ & $33(41,3)$ & $23(46)$ & 0,016 \\
\hline Масса тела, кг & $72 \pm 14,6$ & $85,12 \pm 17,5$ & $88,9 \pm 16,03$ & $<0,001$ \\
\hline 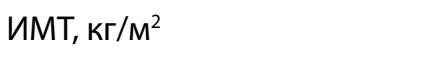 & $25,2 \pm 4,0$ & $30,01 \pm 4,89$ & $30,28 \pm 5,42$ & $<0,001$ \\
\hline OT, сM & $83,3 \pm 12,5$ & $94,84 \pm 14,52$ & $102,7 \pm 13,82$ & $<0,001$ \\
\hline ОБ, см & $101,7 \pm 8,1$ & $107,85 \pm 8,49$ & $106,8 \pm 13,8$ & $<0,001$ \\
\hline ОТ/ОБ & $0,81 \pm 0,09$ & $0,87 \pm 0,09$ & $0,96 \pm 0,08$ & $<0,001$ \\
\hline Нормальная масса тела, \% & $94(54)$ & $13(16,2)$ & $9(18)$ & $<0,001$ \\
\hline Избыточная масса тела, \% & $60(34,5)$ & $33(41,3)$ & $20(40)$ & 0,527 \\
\hline Ожирение, \% & $20(11,5)$ & $34(42,5)$ & $21(42)$ & $<0,001$ \\
\hline САД, мм рт.ст. & $120,5 \pm 15,7$ & $131,88 \pm 15,48$ & $131,76 \pm 14,73$ & $<0,001$ \\
\hline ДАД, мм рт.ст. & $75,4 \pm 9,5$ & $81,04 \pm 9,21$ & $83,02 \pm 11,35$ & $<0,001$ \\
\hline Наличие АГ, n (\%) & $23(13,2)$ & $32(40)$ & $21(42)$ & $<0,001$ \\
\hline $\mathrm{HbA}_{1 c^{\prime}} \%$ & $5,09 \pm 0,43$ & $5,18 \pm 0,58$ & $7,27 \pm 0,69$ & $<0,001$ \\
\hline ГПН, ммоль/л & $5,08 \pm 0,43$ & $5,64 \pm 0,62$ & $8,22 \pm 1,72$ & $<0,001$ \\
\hline ППГ, ммоль/л & $5,22 \pm 1,3$ & $6,63 \pm 1,61$ & $11,52 \pm 3,24$ & $<0,001$ \\
\hline ИРИ, МКЕД/мЛ & $6,1[4,4 ; 7,5]$ & $42,1[28,52 ; 65,07]$ & $10,3[6,6 ; 16,3]$ & $<0,001$ \\
\hline С-пептид, нг/мл & $1,36[1,03 ; 1,68]$ & $7,06[4,7 ; 9,2]$ & $2,67[1,98 ; 3,13]$ & $<0,001$ \\
\hline Индекс HOMA-IR & $1,37[0,96 ; 1,75]$ & $3,25[2,5 ; 4,4]$ & $3,74[2,21 ; 6,64]$ & $<0,001$ \\
\hline
\end{tabular}

*р - критерий Краскела-Уоллиса.

ИМТ - индекс массы тела; ОТ - объем талии; ОБ - объем бедер; САД - систолическое артериальное давление; ДАД - диастолическое артериальное давление; АГ — артериальная гипертония; ГПН — глюкоза плазмы натощак; ППГ — постпрандиальная глюкоза; ИРИ — иммунореактивный инсулин.

из трех групп, отмечался наибольший процент больных АГ $-42 \%$.

Нормальная масса тела (ИМТ $<24,9$ кг/м²) чаще выявлялась в группе здоровых людей (54\%), избыточная масса тела (ИМТ 25-29,9 кг/м²) и ожирение различной

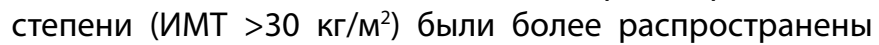
в группе пациентов с ИР и СД2, при этом абдоминальное ожирение (ОТ/ОБ>0,9) было более выражено в группе пациентов с СД2.

\section{Показатели биологии теломер}

ДТ лейкоцитов была измерена у 298 человек. В общем ряду индивидуальных значений относительных величин ДТ лейкоцитов медиана составила 9,76 усл. ед. (интерквартильный размах 9,52-10,02). Все участники исследования со значением ДТ ниже этого показателя были отнесены к группе «коротких» теломер $(n=153)$, равными или выше медианы - к группе «длинных» теломер $(n=145)$.

При ДТ $\leq 9,52$ усл.ед., что соответствовало І квартили распределения (QI ДТ), теломеры считались «самыми короткими» ( $n=77)$, при ДТ $\geq 10,02$ усл. ед., что соответствовало IV квартили распределения (QIV ДТ), теломеры считались «самыми длинными» $(\mathrm{n}=74)$.

АТ удалось оценить у 188 человек. Медиана АТ составила 0,48 усл. ед. (интерквартильный размах 0,31-0,79). Bсе пациенты со значением АТ ниже этого показателя были отнесены к группе «низкой» AT (n=92), равными или выше данного значения - к группе «высокой» АT ( $n=96)$. I квартиль - QI AT («самая низкая» AT), $n=49$, соответствовала AT <0,31 усл. ед., IV квартиль - QIV AT («самая высокая» $\mathrm{AT}), \mathrm{n}=45$, соответствовала $A T>0,79$ усл. ед. 
Характеристики ДТ и АТ в изучаемых группах представлены в таблицах 2 и 3.

Мы видим, что ДТ лейкоцитов достоверно уменьшалась по мере нарастания ИР, процентное превалирование лиц С «короткой» ДТ достоверно нарастало по мере увеличения ИР, доля лиц с «очень короткими» теломерами ( $\leq 9,52$ усл. ед.) была значимо больше в группах пациентов с ИР и СД2.

АТ достоверно снижалась по мере нарастания нарушений углеводного обмена. Доля лиц с очень низкой АТ (QI AT) была значимо больше в группе пациентов с ИР и СД2, доля лиц с очень высокой AT (QIV AT) достоверно снижалась по мере увеличения ИР.
Далее был проведен корреляционный анализ. В группе ИР ДТ достоверно отрицательно связана c $\mathrm{HbA}_{1 c^{\prime}}$ ИРИ и индексом HOMA-IR, а в группе СД2 - достоверно отрицательно связана с $\mathrm{HbA}_{1 c^{\prime}}$ ГПН и индексом HOMA-IR (табл. 4).

Не было выявлено взаимосвязей между АТ и показателями углеводного обмена в зависимости от степени инсулиночувствительности.

Далее был проведен однофакторный логистический регрессионный анализ, где зависимой переменной выступила «короткая» ДТ менее медианы ( $\leq 9,76$ усл. ед.). Результаты представлены в таблице 5.

Таблица 2. Длина теломер в изучаемых группах

\begin{tabular}{lcccc}
\hline \multicolumn{1}{c}{ Показатель } & Здоровые $(\mathbf{n = 1 7 2 )}$ & ИP (n=77) & СД2 (n=49) & P* \\
\hline ДТ, усл. ед. & $9,85[9,59 ; 10,1]$ & $9,7[9,4 ; 9,9]$ & $9,57[9,24 ; 9,83]$ & $<\mathbf{0 , 0 0 1}$ \\
ДТ $\leq 9,76, \mathrm{n}(\%)$ & $69(40,1)$ & $46(59,7)$ & $35(71,4)$ & $<\mathbf{0 0 1}$ \\
QІ ДТ $\leq 9,52, \mathrm{n}(\%)$ & $30(17,4)$ & $26(33,8)$ & $21(42,9)$ & $<\mathbf{0 0 0 1}$ \\
QІV ДТ $\geq 10,02, \mathrm{n}(\%)$ & $50(29,1)$ & $15(19,5)$ & $9(18,4)$ & 0,140 \\
\hline
\end{tabular}

*p - критерий Краскела-Уоллиса.

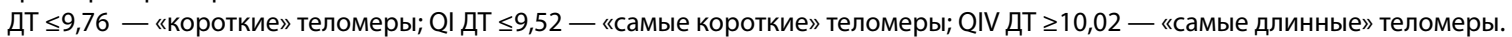

Таблица 3. Активность теломеразы в изучаемых группах.

\begin{tabular}{lcccc}
\hline \multicolumn{1}{c}{ Показатель } & Здоровые $(\mathbf{n = 9 6 )}$ & ИP (n=47) & СД 2 (n=45) & P* \\
\hline AT, усл. ед. & $0,55[0,36 ; 0,85]$ & $0,44[0,34 ; 0,73]$ & $0,32[0,21 ; 0,6]$ & $\mathbf{0 , 0 0 1}$ \\
AT $\leq 0,48, \mathrm{n}(\%)$ & $43(44,8)$ & $24(51,1)$ & $29(64,4)$ & 0,094 \\
QI AT $\leq 0,31, \mathrm{n}(\%)$ & $18(18,8)$ & $10(21,3)$ & $21(46,7)$ & $\mathbf{0 , 0 0 1}$ \\
QIV AT $\geq 0,79, \mathrm{n}(\%)$ & $31(32,3)$ & $9(19,1)$ & $5(11,1)$ & $\mathbf{0 , 0 1 5}$ \\
\hline
\end{tabular}

*р - критерий Краскела-Уоллиса.

AT $\leq 0,48$ - «низкая» активность теломеразы; QI AT $\leq 0,31$ — «самая низкая» активность теломеразы; QIV AT $\geq 0,79$ — «самая высокая» активность теломеразы.

Таблица 4. Взаимосвязи показателей углеводного обмена с длиной теломер в зависимости от степени инсулиночувствительности. Значение коэффициента корреляции Спирмена.

\begin{tabular}{|c|c|c|c|}
\hline \multirow{2}{*}{ Показатель } & Здоровые $(n=173)$ & ИP $(n=80)$ & СД 2 типа $(n=50)$ \\
\hline & дт & дт & дт \\
\hline $\mathrm{HbA}_{1 c^{\prime}} \%$ & $0,02(p=0,71)$ & $-0,22(p=0,04)$ & $-0,22(p=0,12)$ \\
\hline ГПН, ммоль/л & $-0,05(p=0,48)$ & $0,02(p=0,84)$ & $-0,42(p=0,003)$ \\
\hline ИРИ, мКЕД/мЛ & $0,05(p=0,51)$ & $-0,28(p=0,01)$ & $-0,25(p=0,08)$ \\
\hline С-пептид, нг/мл & $-0,11(p=0,54)$ & $-0,17(p=0,16)$ & $-0,14(p=0,32)$ \\
\hline Индекс HOMA-IR & $0,04(p=0,56)$ & $-0,28(p=0,01)$ & $-0,36(p=0,01)$ \\
\hline
\end{tabular}

$\mathrm{HbA}_{1 с}$ - гликированный гемоглобин; ГПН — глюкоза плазмы натощак; ИРИ — иммунореактивный инсулин.

Таблица 5. Ассоциации между длиной теломер и показателями углеводного обмена (однофакторный регрессионный анализ; $\mathrm{n}=298$ ).

\begin{tabular}{llcc}
\hline \multicolumn{1}{c}{ Показатель } & ОШ & $\mathbf{9 5 \% ~ Д И ~}$ & p \\
\hline $\mathrm{HbA}_{1 c^{\prime}} \%$ & 1,65 & $1,26-2,17$ & $<0,001$ \\
ГПН, ммоль/л & 1,56 & $1,26-1,94$ & $<0,001$ \\
ППГ, ммоль/л & 1,07 & $1,02-1,12$ & 0,001 \\
ИРИ, мкЕд/мл & 1,59 & $1,20-2,11$ & 0,001 \\
С-пептид, нг/мл & 1,16 & $1,03-1,34$ & 0,046 \\
Индекс НОМА-ІR & 1,35 & $1,16-1,57$ & $<0,001$ \\
НОМА-ІR>2,5, n (\%) & $1,85-5,14$ & $<0,001$ \\
\hline
\end{tabular}

$\mathrm{HbA}_{1 с}$ - гликированный гемоглобин; ГПН — глюкоза плазмы натощак; ИРИ — иммунореактивный инсулин. 
Таблица 6. Ассоциации между активностью теломеразы и показателями углеводного обмена (однофакторный регрессионный анализ; $\mathrm{n}=188$ ).

\begin{tabular}{lccc}
\hline \multicolumn{1}{c}{ Показатель } & ОШ & $\mathbf{9 5 \% ~ Д И ~}$ & p \\
\hline $\mathrm{HbA}_{1 c^{\prime}} \%$ & 1,46 & $1,09-1,94$ & 0,010 \\
$\Gamma П Н$, ммоль/л & 1,27 & $1,04-1,55$ & 0,017 \\
\hline
\end{tabular}

$\mathrm{HbA}_{1 с}$ - гликированный гемоглобин; ГПН — глюкоза плазмы натощак.

Зависимая переменная - «короткая» ДТ $\leq 9,76$ усл. ед. Все показатели анализировали как протяженные переменные, индекс НОМА — как протяженную переменную и процент пациентов с HOMA-IR $>2,5$.

Однофакторный регрессионный анализ показал, что из всех параметров углеводного обмена наибольшее влияние на риск укорочения ДТ оказывает повышенный индекс HOMA-IR более 2,5 , то есть наличие ИР.

Помимо показателей углеводного обмена, с «короткой» ДТ был ассоциирован возраст (отношение шансов (ОШ) 1,04; 95\% доверительный интервал (ДИ) 1,02-1,06; $\mathrm{p}<0,001)$.

При проведении однофакторного регрессионного анализа с поправкой на возраст все показатели, кроме ППГ, сохраняли свою значимость в качестве предикторов «короткой» ДТ.

УпациентовсСДповышениеуровня $\mathrm{HbA}_{1 с}$ на $1 \%$ увеличивало вероятность выявления «короткой» ДТ в 4,3 раза (ОШ 4,26; 95\% ДИ 1,07-17,02; $p=0,04$ ), повышение уровня ГПН на 1 ммоль/л — на 90\% (ОШ 1,90; 95\% ДИ 1,11-3,24; $\mathrm{p}=0,019)$, повышение индекса HOMA-IR на 1 единицу на 35\% (ОШ 1,35; 95\% ДИ 1,00-1,81; $p=0,047)$.

В результате однофакторного линейного регрессионного анализа с поправками на пол, возраст и ИМТ показано, что из всех параметров углеводного обмена, влияющих на риск «коротких» теломер, наибольшее влияние на риск укорочения ДТ оказывает повышенный индекс HOMA-IR более 2,5, то есть наличие ИР.

Затем был проведен однофакторный логистический регрессионный анализ с поправками на пол, возраст и ИМТ, где зависимой переменной выступила АТ менее медианы ( $\leq 0,48$ усл. ед.). Результаты представлены в таблице 6.

Однофакторный анализ показал, что увеличение уровня $\mathrm{HbA}_{1 \mathrm{c}}$ на $1 \%$ ассоциировалось с увеличением вероятности выявления «низкой» АТ на 46\%, а увеличение уровня ГПН на 1 ммоль/л - на 27\%.

Для уточнения взаимосвязей между степенью нарушения углеводного обмена, ДТ и АТ был проведен однофакторный регрессионный анализ. Зависимыми переменными являлись «короткая» ДТ и «низкая» $\mathrm{AT}$, объясняющей переменной была ранжированная степень инсулиночувствительности: 1 - нет (здоровые), 2 - ИР, 3 - СД2.

Показано, что при увеличении степени нарушений углеводного обмена на 1 ранг вероятность снижения ДТ менее медианы возрастает на 99\% (ОШ 1,99; 95\% ДИ 1,44-2,76; $\mathbf{0}<0,001)$, а риск выявления «очень коротких» теломер возрастает на 94\% (ОШ 1,94; 95\% ДИ 1,39-2,71; $\mathrm{p}<0,001)$.

При увеличении степени нарушений углеводного обмена на 1 ранг вероятность снижения АТ менее медианы возрастает на 53\% (ОШ 1,53; 95\% ДИ 1,03-2,10; $p=0,034)$, а риск выявления «очень низкой» АТ возрастает на $92 \%$
(ОШ 1,92; 95\% ДИ 1,29-2,85; p=0,001). Повышение степени инсулиночувствительности на 1 ранг также снижает вероятность выявления «очень высокой» АТ на $49 \%$ (ОШ 0,51; 95\% ДИ 0,32-0,82; $p=0,005$ ).

\section{ОБСУЖДЕНИЕ}

В данном одномоментном исследовании было показано, что и ДТ, и АТ прогрессивно снижаются по мере усиления ИР. У пациентов с нарушенной инсулиночувствительностью преобладали «короткая» ДТ и «низкая» АТ. Самая «короткая» ДТ и самая «низкая» АТ выявлялись у пациентов с СД2. Вероятнее всего, эти тенденции связаны с антропологическими и метаболическими особенностями пациентов в группах с различной инсулиночувствительностью. Так, в нашем исследовании пациенты в группе СД2 и, соответственно, с более короткими теломерами и более низкой АТ были достоверно старше других участников исследования. А возраст, как известно, является одним из предикторов укорочения ДТ, что было показано в ряде исследований $[11,12]$. Однако, с другой стороны, известно, что основной причиной укорочения ДТ в течение жизни является постепенное усиление активности хронического воспаления и окислительного стресса [13]. А ИР является одним из звеньев этого «патологического круга», инициируя и усугубляя эти процессы и приводя к снижению АТ.

По мере усиления ИР от здоровых лиц до пациентов с СД2 в данном исследовании увеличивалась выявляемость таких факторов, как женский пол, повышение ИМТ и наличие абдоминального ожирения, наличие АГ, которые традиционно относят к факторам риска развития СД2 [6]. С другой стороны, наличие ожирения, особенно абдоминального, АГ являются доказанными факторами риска как укорочения ДТ, так и снижения активности АТ $[14,15]$.

В настоящем исследовании обнаружено, что ДТ и АТ связаны с различными параметрами углеводного обмена. В частности, в группе ИР ДТ отрицательно взаимосвязана с $\mathrm{HbA}_{1 c^{\prime}}$ ИРИ и индексом HOMA-IR, а при СД2 - только с ГПН и индексом HOMA-IR, причем сила взаимосвязи усиливается при переходе ИР в СД 2 типа.

Важным результатом работы является то, что из всех параметров углеводного обмена наибольшее влияние на риск выявления «коротких» теломер оказывает индекс ИР НОМА и его повышение более 2,5. В настоящее время принято считать, что воспаление и окислительный стресс являются объединяющими факторами, объясняющими связь между укорочением ДТ и ИР [16, 17], так как ИР является хроническим состояниям вялотекущего воспаления и окислительного стресса [18]. Воспаление влечет за собой усиление репликации гемопоэтических стволовых клеток, чтобы приспособиться к воспалительной реакции, явлению, которое увеличило бы скорость укорочения ДТ. Поскольку G-триплеты теломер, которые 
содержат повторы TTAGGG, очень чувствительны к гидроксильному радикалу [19], по крайней мере in vitro, окислительный стресс может ускорить укорочение дТ из-за большей потери повторов теломер с каждой репликацией клеток. Следовательно, наличие коротких теломер у взрослых многие исследователи связывают с ускоренным укорочением ДТ, происходящим одновременно с процессами, которые вызывают ИР [20].

Кроме того, ИР сама по себе может быть результатом нарушения дифференциации мезенхимальных прогениторных клеток в зрелые жировые клетки при исходной небольшой ДТ в стволовых клетках [21]. То есть процесс старения клетки может быть одним из звеньев патогенетической цепи при ИР, выступая как в качестве причины, так и в качестве следствия углеводных нарушений, приводя к дальнейшему прогрессированию диабета [22]. А по результатам Фрамингемского исследования установлено, что укорочение теломеры у пациентов с наличием АГ в большей степени ассоциировано с ИР [23], которая неразрывно связана с хроническим воспалением и оксидативным стрессом, также влияющими на укорочение теломер.

Другим важным результатом нашего исследования стало выявление независимых взаимосвязей уровня $\mathrm{HbA}_{1 с}$ с риском выявления «коротких» теломер как в общей группе, так и по отдельности в группах ИР (в 2,4 раза) и СД2 (в 4,26 раза). Кроме этого, в группе СД2 наличие «короткой» ДТ увеличивало риск выявления повышенной ГПН на 90\%. В подтверждение наших выводов, несколько исследований показали обратную корреляцию между ДТ и уровнем глюкозы. В работе Rosa et al. было показано, что у пациентов с недавно диагностированным СД2 относительная ДТ была обратно связана с уровнями ГПН и уровнями $\mathrm{HbA}_{1 с}$ после поправки на возраст, пол и индекс массы тела [24]. В исследовании Ahmad et al. была выявлена обратная связь между ДТ лейкоцитов и ППГ у лиц среднего возраста, не имеющих диабета [25].

Выявленная в исследовании отрицательная взаимосвязь между ДТ и уровнями ГПН и $\mathrm{HbA}_{1 с}$ может свидетельствовать о негативном повреждающем эффекте даже ранних и незначительных изменений метаболизма глюкозы на параметры клеточного старения. Однако не вполне известно, происходит ли это в результате влияния антропометрических факторов или влияния образа жизни (диета, физическая активность) [26]. Среди множества причин наличия более коротких теломер при СД большинство авторов связывают с такими процессами, как хроническая гипергликемия, повышение продукции свободных жирных кислот, накопление конечных продуктов гликирования, усиление активности окислительного стресса, активация ренин-ангиотензин-альдостероновой системы (РАAC) и путей протеинкиназы-С и нарушения в инсулиновом сигнальном пути $[27,28]$. Также наличие очень короткой ДТ при СД2 объясняет и ускоренное старение эндотелиальных и гладкомышечных клеток сосудов при повышении уровня глюкозы [29]. Кроме того, усиление окислительного стресса при диабете сопровождается не только укорочением ДТ, но и снижением АТ [30]. К сожалению, остается открытым вопрос первоочередности: укорочение теломер является результатом метаболических нарушений или наоборот - играет первостепенную па- тогенетическую роль в развитии и прогрессировании ИР и диабета?

Третьим важным результатом нашего исследования стало выявление факта, что нарастание ИР повышает риск выявления «низкой» АТ на 53\% и «очень низкой» АТ на 92\%. В то же время снижение степени ИР повышает шанс повышения АТ до «очень высокой» на 51\%. К сожалению, клинических исследований АТ в мировой литературе крайне мало. А в экспериментальных исследованиях показана прямая причинная взаимосвязь между снижением АТ и нарушением инсулиночувствительности, а также нарушенной толерантностью к глюкозе у Terc-/-G4 мышей [31]. Кроме того, у мышей с генетически детерминированными короткими теломерами нарушены толерантность к глюкозе и передача сигналов бета-клеток, несмотря на массу интактных бета-клеток [32].

Результаты нашего исследования согласуются с тем, что короткие теломеры при состояниях с пониженной АТ связаны с СД2 [33, 34, 35] и у людей. Помимо этого, известно, что такие метаболические факторы, как повышенный ИМТ, абдоминальное ожирение, повышение уровня глюкозы связаны с более короткими теломерами и более низкой AT [36, 37]. B работе Daubenmier et al. было показано, что снижение уровня ГПН было связано с более высокими уровнями АТ [38].

\section{Ограничения исследования}

Поперечный характер исследования, не позволяющий установить характер взаимосвязи «причина-следствие» между углеводным обменом и биологией теломер; отсутствие данных о взаимосвязи постпрандиальной гликемии с биологией теломер, что позволило бы еще глубже охарактеризовать полученные взаимосвязи.

\section{ЗАКЛЮЧЕНИЕ}

В заключение следует отметить, что старение - это прогрессирующее метаболическое и структурное изменение внутренней среды человека, которое является следствием различных причин, включающих совокупное бремя окислительного стресса и хронического воспаления. ИР и СД2 ускоряют процессы старения, поскольку они представляют собой состояния повышенного окислительного стресса и воспаления, которые приводят к сокращению продолжительности жизни. В результате проведенного исследования можно сделать вывод, что различная степень ИР и нарушение углеводного обмена неразрывно связаны с процессами репликативного клеточного старения, в частности с укорочением ДТ. Более короткие теломеры ассоциированы с более выраженными нарушениями углеводного обмена и более высокой степенью ИР вплоть до развития СД2.

Безусловно, перспективным является продолжение исследования с учетом поиска точки преломления и инициации укорочения теломер и снижения активности теломеразы, определения наиболее значимого по аффинитету фактора риска и возможности влияния на длину теломер и активность теломеразы.

Наши результаты подчеркивают ценность исследования биологии теломер для определения персонифицированной тактики коррекции нарушений углеводного обмена. 


\section{ДОПОЛНИТЕЛЬНАЯ ИНФОРМАЦИЯ}

Источник финансирования. Исследование было выполнено за счет собственных средств ФГУ ГНИЦПМ (self-founding).

Конфликт интересов. Авторы декларируют отсутствие явных и потенциальных конфликтов интересов, связанных с публикацией настоящей статьи.

Участие авторов. Дудинская Е.Н. - разработка концепции и дизайна исследования, набор участников исследования, анализ и интерпретация данных, проверка критически важного интеллектуального содержания, подготовка статьи, чтение и одобрение финальной версии статьи перед публикацией; Ткачева О.Н. - разработка концепции и дизайна исследования, проверка критически важного интеллектуального содержания, чтение и одобрение финальной версии статьи перед публикацией; Браилова Н.В. - набор участников исследования, чтение и одобрение финальной версии статьи перед публикацией; Стражеско И.Д. - разработка дизайна исследования, набор участников исследования, подготовка статьи, чтение и одобрение финальной версии статьи перед публикацией; Шестакова М.В. - разработка концепции и дизайна исследования, проверка критически важного интеллектуального содержания, чтение и одобрение финальной версии статьи перед публикацией.

Все авторы прочли и одобрили финальную версию статьи перед публикацией.

\section{СПИСОК ЛИТЕРАТУРЫ | REFERENCES}

1. Стражеско И.Д. Возраст-ассоциированные изменения артериальной стенки: взаимосвязь с гормональнометаболическим статусом и биологией теломер: Автореф. дис. ... докт. мед. наук. - М., 2019. - 42 с. [Strazhesko ID. Vozrastassotsiirovannyye izmeneniya arterial'noy stenki: vzaimosvyaz's gormonal'no-metabolicheskim statusom i biologiyey telomere. [dissertation abstract] Moscow; 2019. 42 p. (In Russ.)]. Доступно по: http://rsmu.ru/fileadmin/templates/DOC/Disser/2019/strazhesko_ id/a_strazhesko_id.pdf. Ссылка активна на 24.06.2020.

2. Fyhrquist F, Saijonmaa O. Telomere length and cardiovascular aging. Ann Med. 2012;44(Suppl 1):138-142. doi: 10.3109/07853890.2012.660497.

3. Bodnar AG, Ouellette M, Frolkis M, et al. Extension of life-span by introduction of telomerase into normal human cells. Science. 1998;279(5349):349-352. doi: 10.1126/science.279.5349.349.

4. Aviv A, Valdes A, Gardner JP, et al. Menopause modifies the association of leukocyte telomere length with insulin resistance and inflammation. J Clin Endocrinol Metab. 2006;91(2):635-640. doi: 10.1210/jc.2005-1814.

5. Satoh M, Ishikawa Y, Takahashi Y, et al. Association between oxidative DNA damage and telomere shortening in circulating endothelial progenitor cells obtained from metabolic syndrome patients with coronary artery disease. Atherosclerosis. 2008;198(2):347-353. doi: 10.1016/j.atherosclerosis.2007.09.040.

6. Madeira IR, Carvalho CN, Gazolla FM, et al. [Cut-off point for Homeostatic Model Assessment for Insulin Resistance (HOMA-IR) index established from Receiver Operating Characteristic (ROC) curve in the detection of metabolic syndrome in overweight prepubertal children. (In Portuguese)]. Arq Bras Endocrinol Metabol. 2008;52(9):1466-1473. doi: 10.1590/s0004-27302008000900010.

7. Дедов И.И., Шестакова М.В., Майоров А.Ю., и др. Алгоритмы специализированной медицинской помощи больным сахарным диабетом. 9-й выпуск // Сахарный диабет. - 2019. - Т.22. №S1-1. - C. 1-144. [Dedov II, Shestakova MV, Mayorov AYu, at al. Standards of specialized diabetes care. Edited by Dedov II, Shestakova MV, Mayorov AYu. 9th edition. Diabetes mellitus. 2019;22(S1-1):1-121. (In Russ.)]. doi: 10.14341/DM221S1.

8. Cawthon RM. Telomere measurement by quantitative PCR. Nucleic Acids Res. 2002;30(10):47. doi: 10.1093/nar/30.10.e47

9. Браилова Н.В. Взаимосвязь состояния сосудистой стенки, углеводного обмена и биологии теломер: Автореф. дис. ... канд. мед. наук. - M., 2017. - 25 c. [Brailova NV. Vzaimosvyaz' sostoyaniya sosudistoy stenki, uglevodnogo obmena i biologii telomer. [dissertation abstract] Moscow; 2017. 25 p. (In Russ.)]. Доступно по: https://search.rsl.ru/ru/record/01008709891. Ссылка активна на 24.06.2020.

10. Дудинская Е.Н., Ткачева О.Н., Шестакова М.В., и др. Длина теломер и состояние сосудистой стенки у пациентов с сахарным диабетом 2 типа // Сахарный диабет. - 2014. - №3. - C. 31-38. [Dudinskaya EN, Tkacheva ON, Shestakova MV, et al. Telomere length and vascular wall in patients with type 2 diabetes mellitus. Diabetes mellitus. 2014;(3):31-38. (In Russ.)]

11. Fasching $\mathrm{CL}$. Telomere length measurement as a clinical biomarker of aging and disease. Crit Rev Clin Lab Sci. 2018;55(7):443-465. doi: 10.1080/10408363.2018.1504274.

12. Rizvi S, Raza ST, Mahdi F. Telomere length variations in aging and age-related diseases. Curr Aging Sci. 2014;7(3):161-167. doi: $10.2174 / 1874609808666150122153151$.
13. Стражеско И.Д., Ткачева О.Н., Акашева Д.У., и др. Взаимосвязь между факторами риска сердечно-сосудистых заболеваний и длиной теломер лейкоцитов // Кардиоваскулярная терапия и профилактика. — 2016. - Т.15. - №3. - С. 52-57. [Strajesko ID, Tkacheva IN, Akasheva DU, et al. Relation of cardiovascular risk factors and leukocyte telomere length. Cardiovascular therapy and prevention. 2016;15(3):52-57. (In Russ.)]. doi: 10.15829/1728-8800-2016-3-52-57.

14. Mundstock E, Sarria EE, Zatti H, et al. Effect of obesity on telomere length: Systematic review and meta-analysis. Obesity (Silver Spring). 2015;23(11):2165-2174. doi: 10.1002/oby.21183.

15. Welendorf C, Nicoletti CF, Pinhel MA, et al. Obesity, weight loss, and influence on telomere length: New insights for personalized nutrition. Nutrition. 2019;66:115-121. doi: 10.1016/j.nut.2019.05.002.

16. Aviv A. Genetics of leukocyte telomere length and its role in atherosclerosis. Mutat Res. 2012;730(1-2):68-74 doi: 10.1016/j.mrfmmm.2011.05.001.

17. Avogaro A, de Kreutzenberg SV, Fadini GP. Insulin signaling and life span. Pflugers Arch. 2010;459(2):301-314 doi: 10.1007/s00424-009-0721-8.

18. Hajjar DP, Gotto AM. Biological relevance of inflammation and oxidative stress in the pathogenesis of arterial diseases. Am J Pathol. 2013;182(5):1474-1481. doi: 10.1016/j.ajpath.2013.01.010.

19. Von Zglinicki T. Oxidative stress shortens telomeres. Trends Biochem Sci. 2002;27(7):339-344. doi: 10.1016/s0968-0004(02)02110-2.

20. Verhulst S, Dalgard C, Labat C, et al. A short leucocyte telomere length is associated with development of insulin resistance. Diabetologia. 2016;59(6):1258-1265. doi: 10.1007/s00125-016-3915-6.

21. Бойцов С.А., Стражеско И.Д., Акашева Д.У., и др. Инсулинорезистентность: благо или зло? Механизмы развития и связь с возраст-ассоциированными изменениями сосудов // Кардиоваскулярная терапия и профилактика. 2013. - T.12. — №4. - C. 91-97. [Boytsov SA, Strazhesko ID, Akasheva DU, et al. Insulin resistance: good or bad? Development mechanisms and the association with age-related vascular changes. Cardiovascular therapy and prevention. 2013;12(4):91-97. (In Russ.)]. doi: 10.15829/1728-8800-2013-4-91-97.

22. Olivieri F, Albertini MC, Orciani M, et al. DNA damage response (DDR) and senescence: shuttled inflamma-miRNAs on the stage of inflammaging. Oncotarget. 2015;6(34):35509-35521. doi: 10.18632/oncotarget.5899.

23. Demissie S, Levy D, Benjamin EJ, et al. Insulin resistance, oxidative stress, hypertension, and leukocyte telomere length in men from the Framingham Heart Study. Aging Cell. 2006;5(4):325-330. doi: 10.1111/j.1474-9726.2006.00224.x.

24. Rosa EC, Santos RR, Fernandes LF, et al. Leukocyte telomere length correlates with glucose control in adults with recently diagnosed type 2 diabetes. Diabetes Res Clin Pract. 2018;135:30-36. doi: 10.1016/j.diabres.2017.10.020.

25. Ahmad S, Heraclides A, Sun Q, et al. Telomere length in blood and skeletal muscle in relation to measures of glycaemia and insulinaemia. Diabet Med. 2012;29(10):e377-e381. doi: 10.1111/j.1464-5491.2012.03737.x.

26. Grunnet LG, Pilgaard K, Alibegovic A, et al. Leukocyte telomere length is associated with elevated plasma glucose and $\mathrm{HbA}$ in young healthy men independent of birth weight. Sci Rep. 2019;9(1):7639. doi: 10.1038/s41598-019-43387-0. 
27. Hink U, Li H, Mollnau H, et al. Mechanisms underlying endothelial dysfunction in diabetes mellitus. Circ Res. 2001;88(2):14-22. doi: 10.1161/01.res.88.2.e14.

28. Baynes JW. Role of oxidative stress in development of complications in diabetes. Diabetes. 1991;40(4):405-412. doi: 10.2337/diab.40.4.405.

29. Salpea KD, Humphries SE. Telomere length in atherosclerosis and diabetes. Atherosclerosis. 2010;209(1):35-38. doi: 10.1016/j.atherosclerosis.2009.12.021.

30. Adaikalakoteswari A, Balasubramanyam M, Mohan V. Telomere shortening occurs in Asian Indian Type 2 diabetic patients. Diabet Med. 2005;22(9):1151-1156. doi:10.1111/j.1464-5491.2005.01574.x

31. Kuhlow D, Florian $S$, von Figura $G$, et al. Telomerase deficiency impairs glucose metabolism and insulin secretion. Aging (Albany NY). 2010;2(10):650-658. doi: 10.18632/aging.100200.

32. Guo N, Parry EM, Luo-Sheng L, et al. Short telomeres compromise B-cell signaling and survival. PloS ONE. 2011;6(3):e17858. doi: 10.1371/journal.pone.0017858.

33. Olivieri F, Lorenzi $M$, Antonicelli $R$, et al. Leukocyte telomere shortening in elderly type 2DM patients with previous myocardial infarction. Atherosclerosis. 2009:206(2):588-593. doi: 10.1016/j.atherosclerosis.2009.03.034

34. Salpea KD, Talmud PJ, Cooper JA, et al. Association of telomere length with type 2 diabetes, oxidative stress and UCP2 gene variation. Atherosclerosis. 2010;209(1):42-50. doi: 10.1016/j.atherosclerosis.2009.09.070.

35. Zee RY, Castonguay AJ, Barton NS, et al. Mean leukocyte telomere length shortening and type 2 diabetes mellitus: a case-control study Trans/ Res. 2010;155(4):166-169. doi: 10.1016/j.trsl.2009.09.012.

36. Epel ES, Lin J, Dhabhar FS, et al. Dynamics of telomerase activity in response to acute psychological stress. Brain Behav Immun. 2010;24(4):531-539. doi: 10.1016/j.bbi.2009.11.018.

37. Valdes AM, Andrew T, Gardner JP, et al. Obesity, cigarette smoking, and telomere length in women. Lancet. 2005;366(9486):662-664. doi: 10.1016/S0140-6736(05)66630-5.

38. Daubenmier J, Lin J, Blackburn E, et al. Changes in stress, eating, and metabolic factors are related to changes in telomerase activity in a randomized mindfulness intervention pilot study. Psychoneuroendocrinology. 2012;37(7):917-928. doi: 10.1016/j.psyneuen.2011.10.008

Рукопись получена: 23.06.2020. Одобрена к публикации: 10.08.2020. Опубликована online: 28.09.2020.

\section{ИНФОРМАЦИЯ ОБ АВТОРАХ [AUTHОRS INFO]}

*Дудинская Екатерина Наильевна, к.м.н. [Ekaterina N. Dudinskaya, MD, PhD]; адрес: Россия, 129226, г. Москва, ул. 1-я Леонова, д. 16 [address: 16 1-st Leonova street, 129226 Moscow, Russia];

ORCID: http://orcid.org/0000-0001-7891-6850; eLibrary SPIN: 4985-6315; e-mail: katharina.gin@gmail.com

Ткачева Ольга Николаевна, д.м.н., професcop [Olga N.Tkacheva, MD, PhD, professor];

ORCID: https://orcid.org/0000-0002-4193-688X; eLibrary SPIN: 677476; e-mail: tkacheva@rgnkc.ru

Браилова Наталия Васильевна, к.м.н. [Nataliya V. Brailova MD, PhD]; ORCID: https://orcid.org/0000-0002-1216-0787; eLibrary SPIN: 2900-8384; e-mail: n.kokshagina@mail.ru

Стражеско Ирина Дмитриевна, Д.м.н. [Irina D. Strazhesko, MD, PhD]; ORCID: https://orcid.org/0000-0002-3657-0676; eLibrary SPIN: 9049-7884; e-mail: istrazhesko@gmail.com

Шестакова Марина Владимировна, д.м.н., профессор, академик PAH [Marina V. Shestakova, MD, PhD, professor, academician of RAS]; ORCID: https://orcid.org/0000-0002-5057-127X; eLibrary SPIN: 7584-7015; email: nephro@endocrincentr.ru

\section{ЦИТИРОВАТЬ:}

Дудинская Е.Н., Ткачева О.Н., Браилова Н.В., Стражеско И.Д., Шестакова М.В. Биология теломер и метаболические нарушения: роль инсулинорезистентности и сахарного диабета 2 типа // Проблемы эндокринологии. - 2020. T. 66. — №4. — C. 35-44. doi: https://doi.org/10.14341/probl12510

\section{TO CITE THIS ARTICLE:}

Dudinskaya EN, Tkacheva ON, Brailova NV, Strazhesko ID, Shestakova MV. Telomere biology and metabolic disorders: the role of insulin resistance and type 2 diabetes. Problems of Endocrinology. 2020;66(4):35-44. doi: https://doi.org/10.14341/probl12510 